\title{
Psychological Harassment in the Workplace: Methods of Evaluation and Prevalence
}

\author{
María José Báguena ${ }^{1}$, María Ángeles Beleña ${ }^{1}$, María de la Paz Toldos ${ }^{2, *}$ and David Martínez ${ }^{1}$ \\ ${ }^{I}$ Departamento de Personalidad, Evaluación y Tratamientos Psicológicos. Facultad de Psicología. Universitat de Va- \\ lencia, Avda. Blasco Ibáñez, 21, 46010 Valencia, Spain; ${ }^{2}$ Escuela de Negocios y Humanidades (ENH), Tecnológico de \\ Monterrey, Campus Guadalajara, Mexico
}

\begin{abstract}
Estimates of the prevalence of psychological harassment (mobbing/bullying) in the workplace vary enormously from one country to another. One of the main reasons for this variation is the method of evaluation used to make these estimates. Research on mobbing or bullying at work is basically guided by two methods: the perceived victimization method and the perceived exposure to bullying behaviors method. These methods, and their combination, were used to estimate the prevalence of bullying in a representative sample of the working population $(\mathrm{N}=1730)$ of the Region of Valencia (Spain). The results obtained suggest the following percentages of victims: (i) perceived victimization: $19.5 \%$ $(\mathrm{N}=338)$; (ii) exposure to bullying behavior: $12.8 \%(\mathrm{~N}=221)$; (iii) both methods: $8.4 \%(\mathrm{~N}=146)$. The study offers other results related to the correspondence between the methods, the most and least frequent bullying behaviors, and the gender and status of the bully.
\end{abstract}

Keywords: Bullying at work, prevalence, methods, gender.

\section{INTRODUCTION}

Among the various terms that exist in the literature to designate nonsexual psychological harassment that occurs in the workplace, two have become the most popular: mobbing and bullying at work. Leymann (1990a) defined mobbing as "hostile and unethical communication which is directed in a systematic manner by one or more individuals, mainly toward one individual, who, due to mobbing, is pushed into a helpless and defenseless position and held there by means of continuing mobbing activities". Later, Einarsen (1999) defined bullying at work as "all those repeated actions and practices that are directed toward one or more workers, which are unwanted by the victim, which may be done deliberately or unconsciously, but do cause humiliation, offense, and distress, and that may interfere with job performance, and/or cause an unpleasant work environment". And, most recently, the European Agency for Safety and Health at Work (2002) referred to bullying as "unreasonable and repeated conduct directed at an employee or group of employees which creates a risk to health and safety". This "conduct" includes the actions of an individual or a group, where even the system of work can be used as a means to victimize, humiliate, or threaten.

Figures on prevalence of harassment can be found in the Third European Survey on Working Conditions prepared by Paoli and Merllié (2001). According to this report, in 2000, 9\% of workers in the European Union (not including the new member states) had been the object of bullying. Di Martino et al. (2003) show the oscillations that appear around this $9 \%$

*Address correspondence to this author at the Escuela de Negocios y Humanidades (ENH), Tecnológico de Monterrey, Campus Guadalajara, Av. General Ramón Corona \#2514, Col. Nuevo México. 45201, Zapopan, JAL. Mexico; Tel: +52 (33) 3669 3000, Ext. 2260; Fax: Ext. 2256;

E-mail: mariadelapaz.toldos@itesm.mx depending on the country; the highest prevalence is found in countries such as Finland (15\%), Holland and the United Kingdom (14\%), and Sweden (12\%), in contrast with southern European countries such as Portugal and Italy (4\%) and Spain and Greece $(5 \%)$. When the most affected occupational sectors are considered, this report shows that the highest percentages are found in public administration (14\%) and in education and health care, as well as in the service, transportation, and communications sectors, all of which have a prevalence of $12 \%$. In contrast, among the sectors least affected by the problem are agriculture and fishing (3\%) and construction (5\%) (Di Martino, Hoel, \& Cooper, 2003; Chappell \& Di Martino, 2006).

In a cross-cultural study conducted by the United Nations (Commission for Human Rights), in which seven countries participated (Brazil, Bulgaria, Lebanon, Portugal, South Africa, Thailand, and Australia), the following results about the prevalence of bullying at work were found: $30.9 \%$ in Bulgaria, $20.6 \%$ in South Africa, $10.7 \%$ in Thailand, $22.1 \%$ in Lebanon, $10.5 \%$ in Australia, and $15.2 \%$ in Brazil (Di Martino, 2003). Within the framework of this type of comparison, we mention part of the results of this study: Among 1,919 Finnish workers from the city of Vasa and 1,007 Spanish workers from the city of Valencia, a prevalence of $15 \%$ and $18 \%$, respectively, was found (Varhama, Baguena, Toldos, Beleña, Roldan, Diaz, Österman, \& Björkqvist, 2010).

If we look at some of the studies conducted in Spain, the most extensive were carried out by Piñuel and Oñate (2002) and by Piñuel (2004). The first of these was conducted with a sample of 2,410 workers representative of the general population, though with a large contingent of service-sector employees. It was found that $16 \%$ had been exposed to bullying. From the perspective of the victim, the bullies were mainly bosses $(82 \%)$ and colleagues (16\%). In addition, in 
$47 \%$ of the cases the bullying had lasted more than a year, and in $30 \%$, two or more years. The bullying behaviors most frequently reported by the victims were: "assignment of meaningless tasks" or "tasks beneath the competence of the worker," "subjection to pressure," and "systematic efforts to devalue the person".

Piñuel's (2004) study was conducted with a sample of 6,800 public service employees, specifically from the Tax and General Auditing Agency of the State Administration. The study, conducted over the Internet, included workers from all of the Autonomous Regions, though a considerably larger representation from the Region of Madrid. According to the study, $21 \%$ of the municipal employees surveyed presented what the author calls a "technical situation" of bullying. The Region-by-Region results are not reliable due to the scant participation of municipal employees in many of the Regions.

Other studies carried out in Spain were conducted by Moreno et al. (2005) with a small sample of workers (103) from the Transportation and Communication Sector of the Region of Madrid. This study found the percentage of bullying victims to be $26 \%$. Justicia et al. (2007) conducted a study with 325 faculty and administration/service employees of the University of Granada, who answered the questionnaire via the Internet. The study found that $11 \%$ were victims of bullying. And Herranz et al. (2006) obtained a figure of $22 \%$ in a sample of university professors at the University of Alicante $(\mathrm{N}=252)$.

The variation in prevalence of bullying found among countries is due to two fundamental reasons. The first is related to cultural differences; certain bullying activities can be tolerated more in some countries than in others. These differences can lead to a distorted representation of reality, such that those countries that have a clearer awareness of the problem appear to be statistically "penalized" when compared with those that have paid less attention to this problem. The second reason, which is even more basic than the first because it influences the differences in prevalence observed not only among countries but also within each country, is related to the method employed by the researcher to evaluate the bullying and to the strategies (frequency and duration of behaviors) used to define whether or not a subject is considered a victim of bullying.

In terms of evaluation, research on psychological harassment in the workplace has been guided basically by two methods: the perceived victimization method, based on research by Olweus (1994) in the area of school violence, and the perceived exposure to bullying behaviors method, based on research by Leymann (1990a, 1990b, 1992). In the first of these methods, usually respondents are presented with a definition of bullying and then asked if they have been victims of such an experience. This is the logic followed by the Psychological Workplace Inventory (PWI) of Björkqvist and Österman (1998). In the second method, the respondents are presented with a group of items that measure specific types of bullying behaviors and then asked to indicate whether they have been regularly exposed to these behaviors during the past six months. Various researchers use this method, employing the LIPT (Leymann Inventory of Psychological Terror) of Leymann (1990b) or similar questionnaires, such as the NAQ (Negative Acts Questionnaire) of Einarsen and
Rakness (1997) or its revised version, the NAQ-R (Negative Acts Questionnaire Revised) (Einarsen \& Hoel, 2001), the WHS (Work Harassment Scale) of Björkqvist and Österman (1998), and the WARQ (Workplace Aggression Research Questionnaire) of Harvey and Keashly (2003).

It is important to point out that the when applying these methods, an intra-method variation is also seen. In the perceived victimization method, subjects can be presented with an operational definition of bullying at work and then decide whether to label their experiences as such, or they can simply be asked whether they have been harassed at work, without being presented the definition. The exposure to bullying behaviors method can vary in its application but is concerned with the frequency and duration of the bullying conducts experienced.

It is this variability in strategies and procedures that allows considerable fluctuation among different studies, as is evident in a review carried out by Nielsen et al. (2010). Let's look at some examples of the discrepancies initially observed. Usually, studies that use the LIPT and the NAQ state that a person is considered a victim of bullying when he or she responds to at least one item of the questionnaire with a frequency of weekly and during the past six months. Zapf et al. (2003) conclude that when this procedure is used, results tend to be between $3 \%$ and $7 \%$ of respondents who report being victims of bullying. Nevertheless, when this strategy has been used in other studies, more extreme rates have been found (Niedl, 1996; Piñuel, 2004; Piñuel \& Oñate, 2002). In addition, this strategy can be used with "stricter" criteria (the negative behaviors occur "three or four times a week and continue for at least six months"), as in the study conducted in Denmark by Agervold (2007), which obtained a prevalence figure of less than $3 \%$, or it can be used with "more relaxed" criteria (not with a frequency of "once, twice, three times, or four times a week in the last six months" but "occasionally in the last six months").

In general, these studies find rates of between $1 \%$ and $4 \%$ of severe bullying against rates of around $10 \%$ of cases in which the respondent has experienced occasional bullying (Einarsen \& Skogstad, 1996; Hoel \& Cooper, 2000). In other studies the participant is asked directly if he or she "has been a victim of mobbing during the last six months." This is the strategy that produces a larger percentage of cases, since about $25 \%$ of people answer this question affirmatively, which could be due to the non-technical use of the terms in everyday language, causing minor conflicts that occur regularly in the workplace to be confused with bullying (Zapf \& Einarsen, 2005). This was the procedure used, for example, in the study of Herranz et al. (2006). Recently, a metaanalysis study carried out by Nielsen et al. (2010) concluded that the perceived victimization method without the use of an operational definition was that which resulted in the highest rate of prevalence (18\%), followed by the exposure to bullying behaviors method applying Leymann's criteria ("once a week in the last six months") (15\%), and the perceived victimization method with the use of an operational definition, which resulted in a lower rate of prevalence (11\%). Finally, in other studies the methods of exposure and perceived victimization have been combined, which has resulted in a smaller number victims (Mikkelsen \& Einarsen, 2001; Salin, 2001). 
Consistent with this last type of study, this study has combined the use of both methods to establish the current prevalence of bullying in the Region of Valencia (Spain). We have been guided by the premise that the essential element of the definition of bullying is that the person not only is exposed to negative behaviors, but also perceives him or herself as victimized by such behaviors. Therefore, in order to arrive at a more reliable indicator of the problem, this study has used the exposure to bullying behaviors method first, and then filtered the results through the perceived victimization method, i.e., the perception of the person who is being victimized by bullying behaviors, which has allowed us at the same time to create cut-off points for the WHS (Work Harassment Scale), similar to what Notelaers and Einarsen (2009) proposed for the NAQ-R (Negative Acts Questionnaire Revised). Nevertheless, we will also present the results obtained from each of these methods separately, keeping in mind that the exclusive use of the perceived victimization method in this study leads us to evaluate victimization by bullying at some time in the working life of the participant and not during the last six months, as is the case when the exposure to bullying behaviors method is used. The perceived victimization method was the method used in the results presented by Varhama et al. (2010).

Finally, two of the sociodemographic variables that are usually explored in this context are those related to the gender and status of the bully. As for the gender of the bully, the evidence is contradictory. On one hand, some studies suggest that men appear as bullies in greater proportion than women (Einarsen \& Skogstad, 1996; Zapf, Einarsen, Hoel, \& Vartia, 2003). One possible explanation that has been given for this result is that workplace bullying includes direct forms of aggression (jokes, humiliation, public ridicule) that would be more typical of men than women, who prefer to use more indirect forms of aggression (isolation of the victim, gossip, manipulating others to carry out bullying activities). In other words, women would use a "relational" style of bullying, in which tactics of social exclusion are primary. On the other hand, other studies find no differences related to the gender of the bully (Leymann, 1990a).

As for status, Zapf et al. (2003) indicate two general tendencies depending on whether the study was conducted in the United Kingdom or in the Scandinavian countries. In the first case, the bully in most cases is a worker who occupies a higher position in the workplace hierarchy. In the second case, in general, bullying originates from superiors and equals in equal parts, with bullying originating from a subordinate in a small number of cases.

\section{METHOD}

\section{Sample}

The study was conducted with a sample of 1,730 workers (810 women and 920 men) representative of the working population in the Region of Valencia. The participants worked in both the public $(\mathrm{N}=999)$ and private $(\mathrm{N}=761)$ sectors. As for age, the sample was mostly made up of young, productive adults, the age categories most represented being those of 25-29 years (24.8\%), 30-34 years (18.9\%), and 35-39 years (15.4\%). The occupational groups most represented, according to the International Standard Classification of Occupations (ISCO-88), were "mid-level technicians and professionals" (51\%), "office employees"
(13\%), and "scientific and intellectual professionals" (10\%). As for experience in the current job, around $43 \%$ of the workers had 1-5 years of experience, while close to $11 \%$ occupied the extreme of less than one year of experience, and close to $8 \%$ the other extreme of more than 20 years of experience. Only $4 \%$ of the workers came from another country.

\section{Instruments}

\section{Data Sheet of Demographic and Vocational Statistics}

For the purposes of this study, a sheet was created which includes "hard" data such as sex and age of the participants, and vocational data such as type and size of the company, occupation, work experience, etc. The form used to gather this information, as well as some of the questions used in the form, was taken from the typical information-gathering forms used by the International Labour Organization (ILO).

\section{Psychosocial Workplace Inventory (PWI)}

Developed by Björkqvist and Österman (1998), the questionnaire explores five variables: conflict at work, burnout, mobbing, sexual harassment, and alcohol consumption. For this study, only the section corresponding to mobbing was used. This instrument follows the logic of the perceived victimization method: the individual is presented with a definition of mobbing and decides whether or not his or her experience can be labeled as such. The PWI allows the identification of groups of subjects according to the level of severity of the harassment situation experienced. So, the levels of severity would reflect a continuum of violence that ranges from aggressions that are more subtle and indirect (Level I) to those that are more direct (Level II), and finally those that can lead to the dehumanization of the worker (Level III). While this questionnaire allows us to ask about whom the participant has had the harassment experience (sex and status of the bully), it does not ask about the frequency or duration of the harassment experience; therefore, with this instrument we would be considering exclusively individuals who have been victims of mobbing at some moment in their working life, but not necessarily in the last six months.

\section{Work Harassment Scale (WHS)}

Developed by Björkqvist and Österman (1998), this questionnaire used 26 items ( 24 from the original version and 2 added for this study) to evaluate the frequency of the exposure of the worker to bullying activities (e.g., excessive criticism, offensive comments about one's private life, ridicule in front of others, etc.) in the last six months. This instrument permits an evaluation of bullying from the perspective of the method of exposure to bullying behavior (objective method). There are five answer choices for each item: never (0), rarely (1), occasionally (2), often (3), and very often (4). Previous analysis conducted by Báguena et al. (2010) permit us to group the items in four rational-empirical categories: attacks on the victim using organizational means ( $\alpha=0.77$ ), attacks on the social relationships of the victim using social isolation ( $\alpha=0.93)$, attacks on the private life of the victim $(\alpha=0.90)$, and verbal aggression $(\alpha=0.92)$. The reliability of this scale yields a very satisfactory value $(\alpha=$ 0.97).

\section{Procedure}

The sample was obtained through two massive applications of the questionnaire during 2004 and 2005. In the first 
application 1,700 questionnaires were distributed and 1,055 (62\%) correctly completed questionnaires were collected. In the second application 1,150 questionnaires were distributed and $675(58.7 \%)$ were collected. The method used to obtain the sample demanded contact with diverse institutions and companies, both public and private. This contact was established with those persons in the institutions who had the authority to grant us permission to carry out the gathering of information. Another part of the sample was obtained through the participation of workers in training courses with various purposes.

Once the contact was established, and according to agreement with the person responsible, the gathering of information proceeded with two methods. In the first method, a number " $x$ " of envelopes, each containing the questionnaire and instructions, was given to the company contact. Voluntarily, each worker filled out the questionnaire (or left it blank), put it back in the envelope, closed the envelope, and deposited it in a previously designated place (for example, a cardboard box labeled for that purpose). After a few days, the researcher went to the company and collected the closed envelopes. In the second method, the envelopes with the questionnaire and instructions were distributed directly by the researcher to the workers, who voluntarily filled out the questionnaires at that time. This was the most frequent method when the information was being gathered through group meetings or classes.

\section{RESULTS}

The results have been grouped in three sections, considering the results obtained with each method separately, and their combination.

\section{The Psychosocial Workplace Inventory (PWI): Results Obtained with the Perceived Victimization Method}

The results obtained with the perceived victimization method (PWI) indicated that $19.5 \%$ of the workers $(\mathrm{N}=338)$ reported having been victims of bullying at some moment in their working life. When the level of severity of the harassment experience is considered, the results obtained indicate that $13.3 \%(\mathrm{~N}=230)$ were victims of mild bullying (Level I), $4.5 \%$ (77) of severe bullying, and 1.8\% (31) of very severe bullying (Level III).

In relation to the gender of the aggressor, of these 338 victims, 177 (52\%) reported the bullying as coming mainly from a man, $70(21 \%)$ reported bullying from a woman, and $91(27 \%)$ reported that both men and women had participated in the bullying. As for the status occupied by the aggressor in the workplace hierarchy, in $61 \%$ of the cases (205) the aggressor held a position superior to the victim's, in $19 \%$ (65) the aggressor and victim held equal positions, in 3\% (9) the aggressor held an inferior position, and in $17 \%$ (59) the aggressors held varied positions in the workplace hierarchy.

\section{The Work Harassment Scale (WHS): Results Obtained with the Exposure to Bullying Behaviors Method}

To establish the prevalence of bullying with this scale, the authors of the current study followed the procedure of Leymann (1990b), with the LIPT, and of Einarsen and Rakness (1997), with the NAQ. The criterion employed in these studies consisted in counting those participants who responded to one or more items of the questionnaire with a frequency of weekly and during $t$ he last six months (or more than six months). Following this procedure, the authors counted the number of workers who answered 4 ("very often") to any of the items of the WHS. Results found that $12.8 \%(\mathrm{~N}=221)$ of the workers reported having been exposed to one or more bullying behaviors very often in the last six months. If, instead of counting exposure to one negative behavior, exposure to two or more is counted, the prevalence figure is reduced to $8.9 \%(\mathrm{~N}=154)$, and if exposure to three or more is counted, the results are $7.4 \%(\mathrm{~N}=128)$.

\section{Results Obtained with the Combination of the Two Methods}

To obtain the number of cases in the Region of Valencia, the information that is provided by the WHS and the PWI was combined. As we suggested previously, one essential element of the definition of mobbing is that the person not only is exposed to negative behaviors, but also perceives him or herself as victimized by such behaviors. In other words, a person can admit that he or she is shouted at in the workplace (WHS), but this item, decontextualized from assumptions about victimization by such a psychosocial stressor (as reflected by the PWI), might not have much significance for the worker, or even for an external observer, beyond the fact that such a business practice is not appropriate. In sum, a very conservative and restrictive strategy has been followed, considering current victims of harassment as those workers who fulfilled the following two criteria: (i) having been exposed to one or more bullying behaviors "very often" in the last six months (WHS) and (ii) perceiving themselves as victims of bullying (with answers on the PWI indicating having been a victim of bullying, without consideration of the severity of the victimization).

The results show that of the 221 workers who fulfilled criterion (i), only 146 (66\%) also fulfilled criterion (ii). In other words, despite their exposure to negative behaviors, 75 workers did not label their experience as relating to the process of victimization by bullying. The 146 workers who did label their experience as victimization represent $8.4 \%$ of the total sample of workers who participated in the study $(\mathrm{N}=$ 1,730). A little more than half of them $(\mathrm{N}=76)$ labeled their experience of bullying as severe or very severe (Level II = 50 and Level III = 26), which represents around $4.4 \%$ of the total sample of workers $(\mathrm{N}=1,730)$.

An additional piece of information refers to the type of negative behaviors to which these 146 bullying victims were exposed with high or low frequency. The results show behaviors such as "Belittling your opinions" (67.8\%), "Insinuative glances and/or negative gestures" (65.7\%), "Having your work judged in an incorrect and insulting manner" $63.1 \%$, and "Excessive criticism" (63\%). In the case of least frequent behaviors we find the following: "Accusations of being mentally disturbed" (68.4\%), "Having sensitive details about your private life revealed" (66.4\%), "Not being given any tasks (not having anything to do)" (65\%), and "Being given humiliating tasks $(63 \%)$.

Finally, one additional piece of information that strikes us as extremely interesting comes from putting both methods together with the goal of establishing cut-off points in the WHS, using the PWI as a reference. In other words, the lev- 
els of severity evaluated by the PWI should correspond with progressively higher scores of the workers in the WHS. To see this sensitivity of one method with respect to another, we have followed a simple procedure that consists in dividing the number of victims found in this study $(\mathrm{N}=146)$ into three groups, considering the level of severity of bullying as evaluated by the PWI. Doing this, we obtain three groups of subjects: Level I $(\mathrm{N}=70)$, Level II $(\mathrm{N}=50)$, and Level III $(\mathrm{N}=26)$. These groups were compared in order to observe the types of differences that are produced in the scores obtained by the workers in the WHS, as well as the differences in the factors evaluated by this instrument.

The results are found in Table $\mathbf{1}$ and show that as the level of severity of bullying increases according to the PWI, the scores that workers obtain on the WHS increase also. Significant differences occur between all of the levels of severity of bullying. The measurements obtained by the workers in each level can be used as a reference in this questionnaire when establishing cut-off points (the highest achievable score is 104), such that a score equal to or greater than 49 could indicate exposure to psychological harassment when this scale is used, while a score equal to or greater than 56 could be understood according to the same logic as an indicator that this exposure to harassment was severe. Other suggestions in relation to the comparison between both instruments is found in Báguena et al. (2010).

Regarding the different factors of the WHS, two things can be added. One is that all of the scales differ widely and significantly between the minimum (Level I) and the maximum (Level III) severity of harassment. The most notable differences correspond with the factor connected to verbal aggression $\left(t_{1,96}=-5.20, \mathrm{p}<.001\right)$ and to attacks on the private life of the victim and rumors $\left(t_{1,96}=-3.84, \mathrm{p}<.001\right)$. Another is that between the minimum and intermediate levels of severity, the differences aren't significant for the factors relative to attacks on the victim with organizational means and attacks directed at the private life of the victim, while the intermediate and maximum levels of severity of harassment do not differ significantly in the factor relative to attacks on the social relationships of the victim.

\section{DISCUSSION}

Considering the conservative procedure of analysis that was followed in this study, the main conclusion consists in recognizing that psychological harassment in the workplace, or bullying/mobbing, currently affects at least $8.4 \%$ of the workers in the Region of Valencia. This prevalence figure, differs from that given for Spain by Di Martino et al. (2003) who placed it at 5\%. In any case, this 5\% (more specifically, $4.4 \%$ ) would be the figure that corresponds to the most severe cases of harassment found in our study. But the figure differs much more from the results obtained by Piñuel and Oñate (2002) and by Piñuel (2004), and in this case the discrepancy cannot be explained only by the fact that our strategy was conservative, since even the results we obtained with the same method as those researchers (regular exposure to bullying behaviors during the last 6 months) show a figure of $12.8 \%$, quite far from $21 \%$ (Piñuel, 2004) although a little closer to the figure obtained by that researcher in an earlier study [9]. In addition, this $12.8 \%$ is barely less than the $15 \%$ obtained by Nielsen et al. (2010) in their meta-analysis study.

It is important to emphasize that $19.5 \%$ of the sample reported having been victimized at some point in their working lives (using PWI only), which represents an indicator high enough to seriously consider primary prevention programs directed toward sensitizing managers and workers, thus avoiding the proliferation of this type of violence, which is rarely penalized. This prevention implies, among other things, the development of codes of ethics by companies and institutions, codes that reflect what these organizations will and won't tolerate when it comes to the behavior of their workers. This assumes the development of appropriate procedures to manage complaints, procedures that guarantee that the worker will not be victimized for making a formal complaint. In essence, the results imply the necessity of establishing appropriate and model company practices. If in spite of these practices, cases of harassment are recorded, the organization should have resources and strategies that permit it to deal with the violence. At the same time, the fact that with our conservative analysis procedure (using both the WHS and the PWI) we obtained a figure of prevalence of $8.4 \%$, which corresponds approximately half and half with mild (Level I) and severe (Levels II and III) cases of bullying, justifies the development of secondary and tertiary prevention strategies, respectively. In the case of secondary pre-

Table 1. Levels of Severity in the Psychosocial Workplace Inventory and Differences in the Work Harassment Scale (N = 146)

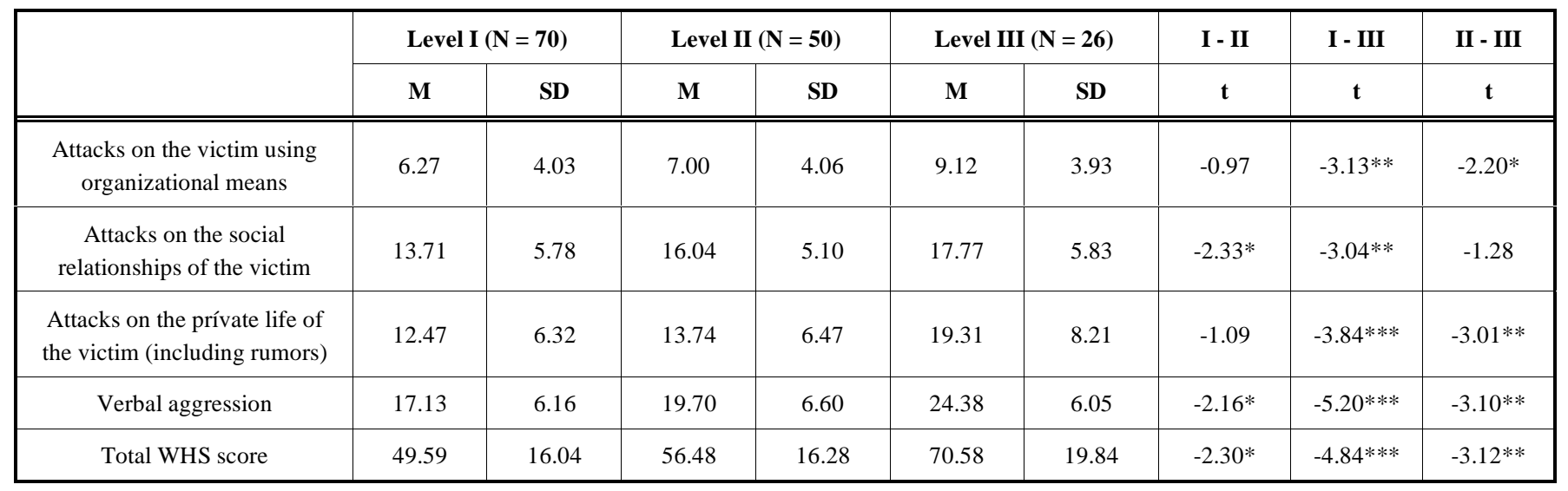

Note- $\mathrm{M}=$ Mean; $\mathrm{SD}=$ Standard Deviation; $\mathrm{t}=$ Student's ' $\mathrm{t}$ '; $*=\mathrm{p}<.05 ; * *=\mathrm{p}<.01 ; * * *=\mathrm{p}<.001$. 
vention, it is important to have mediators who above all are aware that bullying/mobbing is an escalating conflict, a long process in which personal violence increases over time. In the case of tertiary prevention, which is more treatment than prevention, supposes taking measures to ensure that the worker recover his or her health and dignity, which the harassment undermines, and rehabilitate the worker for the working world. There is no doubt that severe cases of harassment require medical and psychotherapeutic treatment.

One question to consider is the decrease observed when only the WHS is used versus when the WHS is used in conjunction with the PWI, where we see the figure fall from $12.8 \%$ to $8.4 \%$. In our judgment, the explanation is found in something just mentioned. Since bullying/mobbing is a process that develops over time, the fact that the individual does not label or perceive his or her experience as victimization (according to the PWI) even when exposed to bullying activities (according to the WHS), does not mean that this experience could not be labeled as victimization at some time in the future. In the narratives of victims who have suffered a process of extreme bullying, one can often appreciate the victim's initial disbelief that he or she could be the object of such victimization. Another possibility is to recognize that the perceived victimization method with the use of an operational definition has more validity for discriminating between victims of bullying and non-victims. From this perspective, it could be argued that looking for overlap between the information collected by the WHS and the PWI to establish the prevalence rate was a good decision, although $8.4 \%$ is slightly less than the $11 \%$ obtained using the perceived victimization method exclusively (Nielsen, Notelaers, \& Einarsen, 2011). In any case, studying the prevalence of bullying starting from the overlap between the two methods has permitted the establishment of cut-off points in the WHS, similar to what Notelaers and Einarsen (2009) did with the NAQ-R, although with a somewhat different procedure.

Considering the results obtained in terms of the gender and status of the bully, several observations should be added. In our study the role of the aggressor is principally played by a man, which in principle is in agreement with most of the study. However, as we have shown in another study (Baguena, Beleña, Toldos, Diaz, Roldan, \& Amigo, 2006) this result fades if the gender of both the bully and the victim is considered. When the victim is a man, another man appears clearly as the main aggressor, whereas when the victim is a woman, the main aggressor may be a man or a woman. One masking effect that should not be forgotten when considering the gender of the aggressor could come from the unequal ratio of men/women with whom the victim works, in that it is more likely that the bully is mainly a man if most of the victim's coworkers are men. As for status, our results point to an intermediate position that falls between the British and Scandinavian studies, since in only $60 \%$ of the cases of bullying did the aggressor occupy a position clearly superior to the victim. These intermediate results have also been obtained by other researchers (Niedl, 1995; Zapf, 1999).

Finally, we would like to conclude with two suggestions. The first, of a more empirical nature, consists in emphasizing how important it is for studies on psychological harassment in the workplace to use both methods to establish the dimension of this occupational health problem. This would help clear up the disparity of the prevalence figures within each country and among different countries. The second, of a more theoretical nature, is related to the levels of severity evaluated in our study through the WPI. Since the evaluation of these levels of severity are intrinsically related to the model of Björkqvist (1992), which suggests that psychological harassment represents a continuum of aggression in three phases that range from the use of indirect strategies of aggression to the most dehumanizing forms of abuse of power, it would be interesting to have a sufficient number of victims in each level of severity in order to see if, effectively, the types of negative behaviors reported by the victims in the WHS and in each phase fit those postulated by such a model.

\section{ACKNOWLEDGEMENT}

This study was conducted thanks to a grant of European funds by the Ministry of Education and Science (SEJ200402871).

\section{CONFLICT OF INTEREST}

None.

\section{REFERENCES}

Agencia Europea para la Seguridad y Salud en el Trabajo (2002). Investigación sobre el estrés relacionado con el trabajo. Luxemburgo. Retrieved December 20, 2010, from http://osha.europa.eu/ ew2002/ presspack//recpc/06/

Agervold, M. (2007). Bulying at work: A discussion of definitions and prevalence, based on an empirical study. Scandinavian Journal of Psychology, 48, 161-172.

Báguena, M. J., Beleña, A., Toldos, M. P., Díaz, A., Roldán, C., \& Amigó, S. (2006). Mobbing, género y salud. Retrieved December 20, 2010, from http://www.migualdad.es/mujer/mujeres/estud_inves/Mobbing genero_salud.pdf//recpc/07

Báguena, M. J., Toldos, M. P., Beleña, M. A., Martínez, D., Díaz, A., Amigó, S., \& Roldán, C. (2010). An analysis of the work harassment scale (WHS) with victims of bullying at work. In K. Österman (Ed.), Indirect and Direct Aggression (pp. 307-318). Peter Lang Publishing Group.

Björkvist, K. (1992). Harassment exists among employees at Abo Academy. Meddelande fran Abo Akademi, 9, 14-17.

Chappell, D., \& Di Martino, V. (2006). Violence at work. 3a. Ed. International Labour Office: Geneva.

Björkqvist, K., \& Österman, K. (1998). Scales for research on interpersonal relationship. Finland: Abo Akademi University. Pro Facultate, 4.

Di Martino, V. (2003). Workplace violence in the Health Sector. Country cases studies. Retrieved December 20, 2010, from www.ilo.org/ public/english/dialogue/sector/papers/health/violence-ccs.pdf//recep/05/

Di Martino, V., Hoel, H., \& Cooper, C. L. (2003). Preventing violence and harrassment in the work place. Luxembourg: Office for Official Publications of the European Communities.

Einarsen, S., \& Hoel, H. (2001). The Negative Acts Questionnaire: Development, validation and revision of a measure of bullying at work. Paper presented at the 10th European Congress on Work and Organizational Psychology. Prague.

Einarsen, S. (1999). The nature and causes of bullying at work. Journal of Manpower, 20, 16-27.

Einarsen, S., \& Raknes, B.I. (1997). Harassment at work and the victimization of men. Violence and Victims, 12, 247-263.

Einarsen, S., \& Skogstad, A. (1996). Bullying at work: Epidemiological findings in public and private organisations. European Journal of Work and Organizational Psychology, 5, 185-201.

Harvey, S., \& Keashly, L. (2003). Predicting the risk for aggression in the workplace: Risk factors, self-esteem and time at work. Social Behavior and Personality, 31, 807-814.

Herranz, J., Reig, A., \& Cabrero, J. (2006). La presencia del mobbing y sus determinantes laborales en profesores universitarios. Análisis y Modificación de Conducta, 32, 145-163.

Hoel, H., \& Cooper, C. L. (2000). Destructive conflict and bullying at work. November, 2000. Unpublished Report, UMIST, UK. 
Justicia, F., Benítez, J. L., Fernández, E., \& Berben, A. G. (2007). El fenómeno del acoso laboral entre los trabajadores de la Universidad. Psicología en Estudio, 12, 457-463.

Leymann, H. (1990a). Mobbing and psychological terror at workplaces. Violence and Victims, 5, 119-126.

Leymann, H. (1990b). Manual of the LIPT questionnaire for assessing the risk of psychological violence at work. Stockholm: Violen.

Leymann, H. (1992). Vuxenmobbing pà svenska arbeidplatser. Stockholm: Arbetarskyddstyrelsen. Delrappot 1 om frekvenser.

Moreno, B., Rodríguez, A., Garrosa, E., Morante, M. E., \& Rodríguez, R. (2005). Diferencias de género en el acoso psicológico en el trabajo: un estudio en población española. Psicología en Estudio, 10, 3-10.

Mikkelsen, G. E., \& Einarsen, S. (2001). Bullying in Danish work life: Prevalence and health correlates. European Journal of Work and Organizational Psychology, 10, 393-413.

Niedl, K. (1995). Mobbing/Bullying am Arbeitsplatz. Eine empirische Analyse zum Phänomen sowie zu personalwirtschaftlich relevanten Effekten von systematischen Feindseligkeiten. Munich: Hampp.

Niedl, K. (1996). Mobbing and well-being: Economic and personnel development implications. European Journal of Work and Organizational Psychology, 5, 239-259.

Nielsen, M. B., Notelaers, G., \& Einarsen, S. (2011). Measuring exposure to workplace bullying. In S. Einarsen, H. Hoel, D. Zapf, C. Cooper (Eds.), Bullying and harassment in the workplace: Developments in theory, research and practice (pp. 149-174). 2nd ed. CRC Press. Taylor \& Francis Group.

Nielsen, M. B., Matthiesen, S. B, \& Einarsen, S. (2010). The impact of methodological moderators on prevalence rates of workplace bullying. A meta-analysis. Journal of Occupational and Organizational Psychology, 83, 955-979.

Notelaers, G., \& Einarsen, S. (2009). Measuring workplace bullying. Paper presented at the Social Tension at Work and Mental Health Workshop, Berlin.
Olweus, D. (1994). Annotation: Bullying at school - basic facts and effects of a school based intervention program. Journal of Child Psychology and Psychiatry, 35, 1171-1190.

Paoli, P., \& Merllié, D. (2001). Third European Survey and Working Conditions 2000. Luxembourg: Office for Official Publications of the European Communities.

Piñuel, I. (2004). Libro Blanco: los riesgos psicosociales en la administración. Madrid: Sindicato Gestha.

Piñuel, I., \& Oñate, A. (2002). La incidencia del mobbing o acoso psicológico en el trabajo en España. Revista de Relaciones Laborales de la $U P V, 7,35-62$.

Salin, D. (2001). Prevalence and forms of bullying among business professionals: A comparison of two strategies for measuring bullying. European Journal of Work and Organizational Psychology, 10, 425-441.

Varhama, L. M., Baguena, M. J., Toldos M. P., Beleña, M. A., Roldan, M. C., Diaz, A., Österman, K., \& Björkqvist, K. (2010). Dysfunctional workplace behavior among municipal employees in Spanish and Finnish cities: A cross-national comparison. Perceptual and Motor Skills, 110(2), 463-468.

Zapf, D. (1999). Mobbing in Organisationen. Ein Überblick zum Stand der Forschung. Zeitschrift für Arbeits and Organisationpsychologie, 43, 125.

Zapf, D., \& Einarsen, S. (2005). Mobbing at work: Escalated conflicts in organizations. In S. Fox, P. E. Spector (Eds.), Counterproductive work behaviour. Investigations of actors and targets (pp. 237-70). Washington, DC: American Psychological Association.

Zapf, D., Einarsen, S., Hoel, H., \& Vartia, M. (2003). Empirical findings on bullying in the workplace. In S. Einarsen, H. Hoel, D. Zapf, C. L. Cooper (Eds.), Bullying and emotional abuse in the workplace (pp. 103 126). London: Taylor \& Francis.

(C) Báguena et al; Licensee Bentham Open.

This is an open access article licensed under the terms of the Creative Commons Attribution Non-Commercial License (http://creativecommons.org/licenses/by-nc/3.0/) which permits unrestricted, non-commercial use, distribution and reproduction in any medium, provided the work is properly cited. 